\title{
Gute und/oder schlechte ärztliche «Manieren»?
}

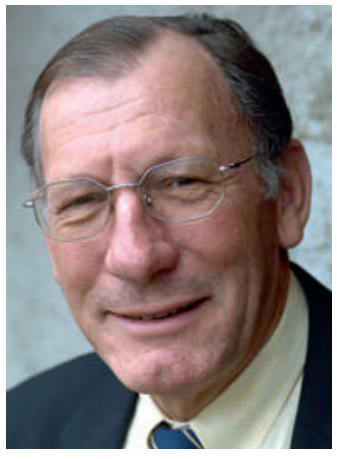

Jean Martin
Ein Chirurg unseres Landes postete kürzlich über «WhatsApp» ein Foto, auf dem er im OP nach einem Eingriff mit blutverschmiertem Kittel und hocherhobenem Arm zu sehen ist. Also in einem typischen Moment seines Berufsalltags. Das hat Aufsehen erregt, und das Spital musste sich zu dem Fall äussern.

In meinem Amt als Kantonsarzt gehörte es zu den Aufgaben, zusammen mit anderen Stellungnahmen zu ungewöhnlichem oder auch tadelnswertem Verhalten von Gesundheitspersonal abzugeben. Interessant ist, welche Aspekte in Betracht zu ziehen sind und welchen Rechten und Interessen verschiedener Personen und Instanzen dabei Rechnung zu tragen ist: Da ist zunächst der Patient, dann der Arzt in seiner Person, der Arzt als Mitglied seines Berufsstandes, die Einrichtung, in der er arbeitet (Spital, Alters- und Pflegeheim usw.), und ggf. noch die Gesundheitsbehörde.

Zunächst gilt es abzuklären, dass die Würde und die (psychische) Integrität des Patienten nicht angegriffen wurden. Dies ist unproblematisch, wenn der Patient weder direkt noch indirekt sichtbar oder identifizierbar ist (im gegenteiligen Fall gestaltet sich die Lage allerdings anders und problematischer, wenn z.B. medizinisches Personal Fotos verbreitet, auf dem es bei der Ausübung seines Berufs zusammen mit bekannten Persönlichkeiten zu sehen ist). Zeigt sich der Arzt wiederum als Privatperson etwa einem grossen Bekanntenkreis in einer ungewöhnlichen Pose, muss er selbst einschätzen, welche Risiken er dabei eingeht. Dabei ist zu bedenken, dass die Situation eine andere ist als in dem Fall der jungen Ärzte, die im Überwachungszimmer («salle de garde» in Frankreich) anzügliche bis hin zu schockierenden, schlüpfrige Exzesse vollführten. Dies geschah zu einer anderen Zeit und unter Ausschluss der Öffentlichkeit. Werden Meldungen und Bilder im grossen Massstab verbreitet, kann dies dem Ruf schaden. Dieses Risiko muss die Person selbst tragen (in den letzten Jahren sind auf der anderen Seite des Atlantiks politische Karrieren daran gescheitert). Des Weiteren kann es sein, dass der Arzt als Mitglied eines Berufsstandes, der mit staatlicher Zulassung praktiziert, sich vor seiner Berufsvereinigung und/ oder der öffentlichen Kontrolbehörde verantworten nach der Auswirkung auf das Verhältnis zum Arbeitgeber.

Das sind die Prinzipien. Abgesehen davon ist es in solchen Fällen auch eine Frage einer gewissen «guten Erziehung», der «guten Manieren» [1]. Die meisten von uns wünschen sich, dass die freien Berufe Seriosität, Korrektheit und einen gewissen Anstand wahren - wenngleich es nicht verboten ist, in weniger förmlicher Kleidung zu praktizieren oder einen weniger gehobenen Sprachstil zu pflegen. Dann ist es Sache des Patienten/der Patientin, darüber zu urteilen, indem er/sie sein/ihr Unbehagen mitteilt oder den Arzt oder Therapeuten wechselt.

Was die «Manieren» anbelangt, so haben sich die Zeiten geändert und damit auch der Status der Ärzte. So wie Geistliche und Lehrer haben sie nicht mehr die Pflicht, als «Würdenträger» aufzutreten. Man erlebt sie als Aktive in zahlreichen verschiedenen Vereinen und Gruppen oder als engagierte politische Vertreter. Die Bandbreite an Verhaltensweisen, die kein Stirnrunzeln mehr verursachen, ist deutlich grösser geworden. Gleichzeitig sind die digitalen Netzwerke eine völlig neue Dimension von erheblicher Tragweite und mit enormen Austausch an Informationen höchst unterschiedlicher Wichtigkeit. Ein Austausch mit ein paar Dutzend oder Hunderten von «Freunden» auf professionellen und privaten Netzwerken oder in der Blogosphäre, durch Kommentare, Fotos oder Clips, die in kürzester Zeit für Millionen sichtbar sind.

Man muss mit der Zeit gehen. Was ist also an einem Arzt oder einer Pflegeperson zu kritisieren, die sich mit «originellen», ungewöhnlichen Umgangsformen oder Kleidern präsentieren? Nichts? Es ist zumindest dann etwas zu sagen, wenn sie eine fragwürdige oder empörende (sexuelle, gewaltsame, vulgäre, extremistische, rassistische) Konnotation haben. Hier wie überall gilt die Grundregel des gegenseitigen Respekts.

Ärzte und ähnliche Berufe sind nicht mehr verpflichtet, in förmlicher Kleidung mit ernster Miene und besonders gemessenem Benehmen aufzutreten. Sie dürfen bei alledem nur nicht vergessen, dass die Medizin und die Pflege ein persönliches Berufsethos, Wissenschaftlichkeit, soziale und fachliche Kompetenzen und das Vertrauen des Patienten erfordern. Wenn diese Berufsvertreter im Licht der Öffentlichkeit stehen, erscheint es ratsam, dass sich der Betrachter - und allen voran der Patient - nicht fragen muss, ob er ihren menschlichen und professionellen Qualitäten noch vertrauen kann.

Jean Martin, Mitglied der Redaktion \begin{abstract}
muss. Handelt es sich um relativ leichte Entgleisungen, so sehen im Allgemeinen die jeweiligen Standesregeln Verfahren vor (wobei man in diesem Fall Sanktionen entgehen kann, indem man aus dem Berufsverband austritt!). In schwereren Fällen kann das kantonale Gesundheitsdepartement ein Untersuchungsverfahren anordnen. Bleibt noch die Frage

siehe: Martin J.

Schwarzer Humor im akzeptabel oder nicht? Schweiz Ärztezeitung. 2011;92(43):1674.
\end{abstract}

